\title{
29. Unusual Chemical Compositions of Noctilucent-Cloud Particle Nuclei
}

Curtis L. Hemenway

Dudley Observatory and

State University of New York at Albany

Albany, New York

\begin{abstract}
On August 8, 1970, two Pandora sounding rocket payloads were launched from the ESRO range in Kiruna, Sweden during a noctilucent cloud display. Large numbers of sub-micron particles were collected, most of which appear to be made up of a highdensity material coated with a low-density material. Typical electron micrographs are shown. Particle chemical compositions have been measured by use of dispersive $x$-ray analysis equipment attached to a Philips EM 300 electron microscope and have revealed that most of the high-density particle nuclei have atomic weights greater than iron.
\end{abstract}

$\mathrm{O}$ AUgust 8,1970 at $1: 48$ and at $3: 54$ local time, two Nike Apache sounding rockets containing Pandora micrometeorite collectors were launched into a noctilucent cloud display above Esrange in Kiruna, Sweden. The visual observation of the noctilucent clouds was carried out by Nathan Wilhelm of Meteorological Institute of Stockholm University and $\mathrm{P}^{-1} \mathrm{nh}$ Carnevale (AFCRL) who were stationes at
Sundsvall, $600 \mathrm{~km}$ south of Esrange. Figure 1 shows a photograph of the noctilucent cloud over Esrange into which the rockets were launched as seen from Sundsvall.

The sampling surfaces as in past Pandora flights (Hemenway and Hallgren, 1970; Hallgren and Hemenway, 1970) consisted of thin nitrocellulose films supported on copper grids. Since in-flight shadowing was used, the grids were

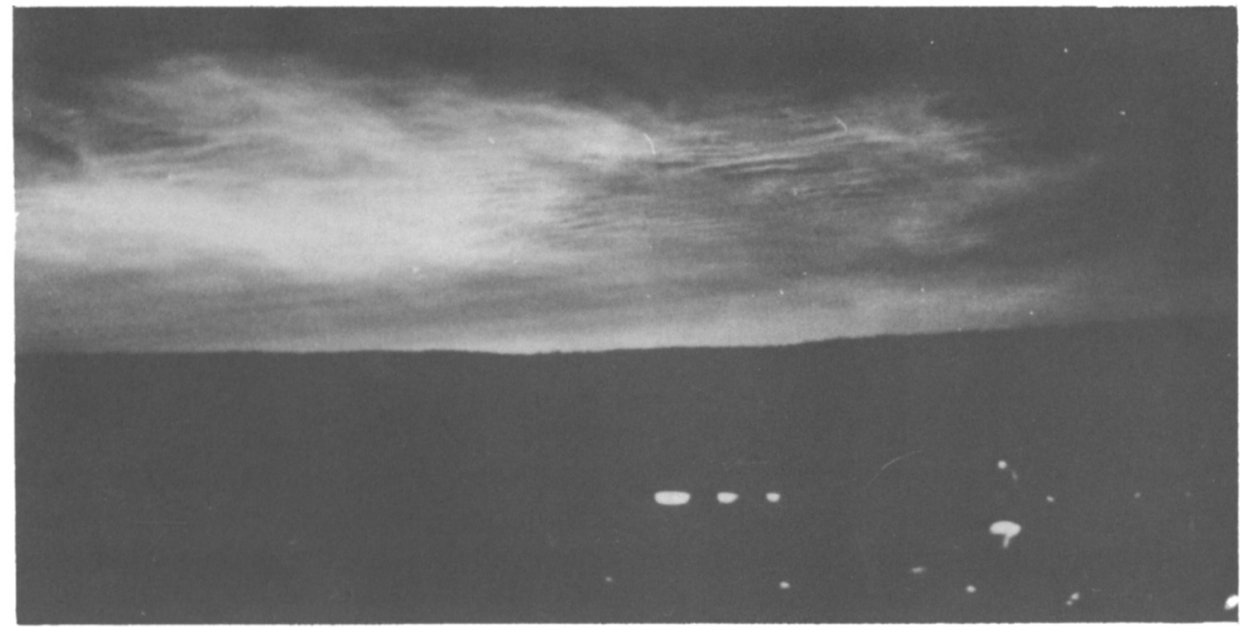

Figure 1.-Photograph of the noctilucent cloud sampled. 
seeded with tungsten oxide particles to act as a monitor of the quality of the shadows.

All payload functions performed as planned but unfortunately the trajectory of each payload was about $10 \mathrm{~km}$ lower than planned, with the result that the shadowing for the first two sampling increments from each payload took place at an altitude where the ambient pressure was too high for producing sharp shadows. For
Pandora $\mathrm{N}$, the first payload launched, the altitudes sampled were 82 to $94 \mathrm{~km}$ and 94 to $124 \mathrm{~km}$ and for Pandora $M$ the altitudes were 85 to $96 \mathrm{~km}$ and 97 to $133 \mathrm{~km}$.

Figure 2 shows examples of an unusual type of particle found in large numbers on Pandora $\mathrm{N}$ and to a lesser extent on Pandora M. The particles generally consist of high-density material surrounded by a round-to-elliptical, droplet-like
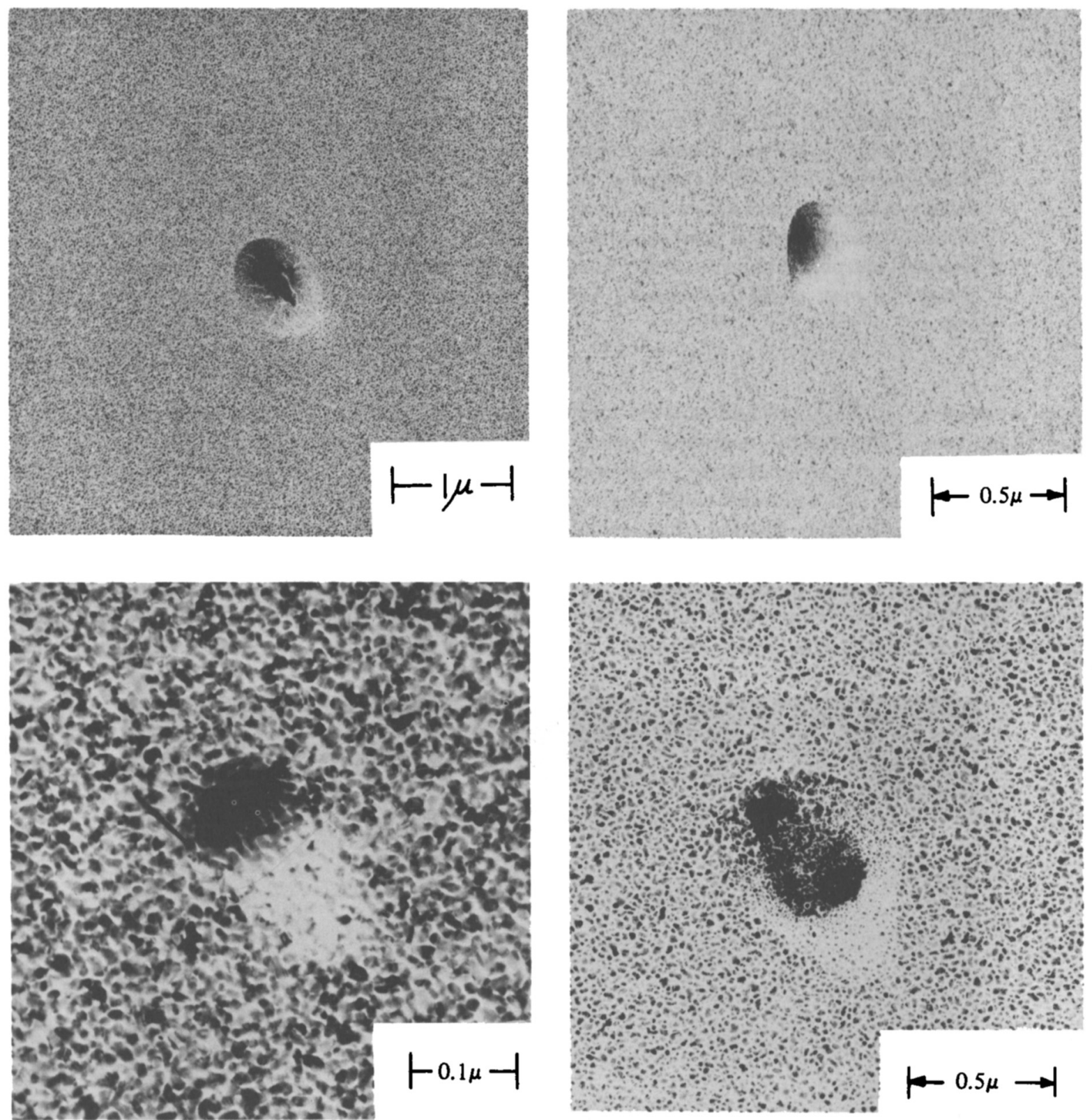

Figure 2.-Electron micrographs of noctilucent cloud particles collected. 
coating of low electron optical density. Approximately 70 percent of the collected particles were of this unusual type. Somewhat similar twocomponent particles were collected during a noctilucent cloud display in 1962 (Hemenway et al., 1962).

By using an $\mathrm{x}$-ray spectrometer attached to our Phillips 300 electron microscope, it has been possible to obtain qualitative chemical analyses from a study of the characteristic x-ray emission from some of the collected particles. Figure 3 shows an example of x-ray spectra of a particle and the nearby background in which the lanthanum lines located at $47.2^{\circ}$ and $48.5^{\circ}$ associated with a noctilucent cloud particle are clear. The remaining lines of tungsten and gold
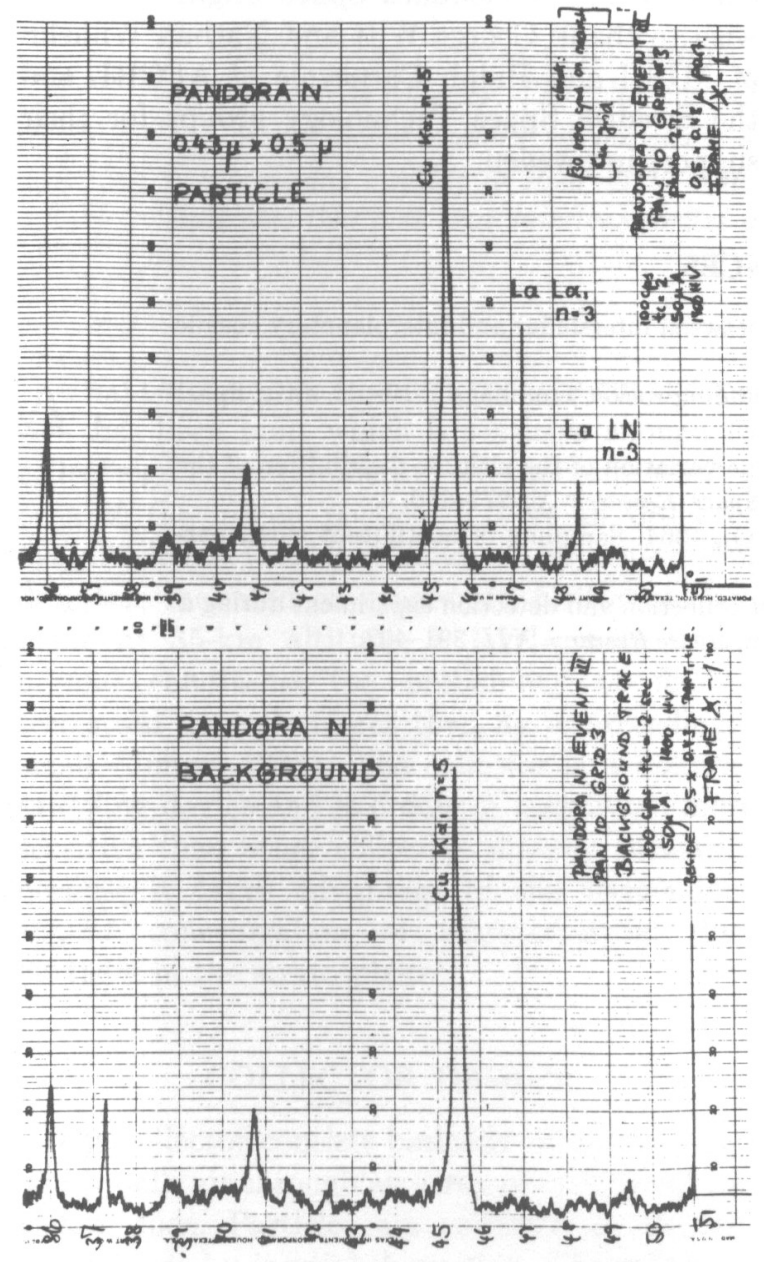

Figure 3.-X-ray spectra of a particle and nearby background. are noted on the left sides of the spectra. Figure 4 shows an additional example of $x$-ray spectra of a particle and nearby background in which a silicon peak at $42.0^{\circ}$ associated with the particle and other peaks of uncertain origin can clearly be seen.

The presence of high atomic number elements is consistent with the high electron-optical density of the nuclei of the coated particles. Tentatively, the following elements have been identified as associated with the haloed particles: lanthanum, silicon, thulium, praseodymium, osmium, ytterbium, and tantalum. There are a number of weak lines which have not been identified and other marginal identifications which have not been included even though they
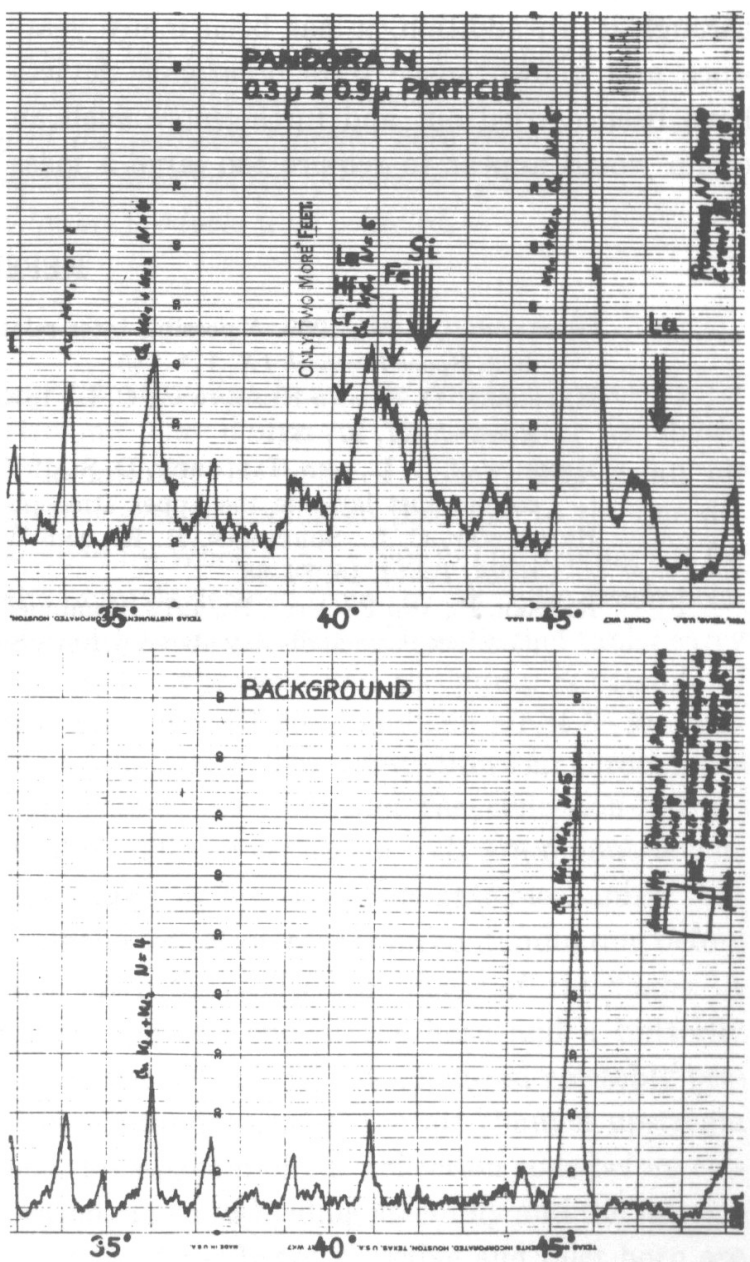

FIgURE 4.-X-ray spectra of a particle and nearby background. 
seem to be mostly high $z$ elements. The one observation which is clear is that the observed $\mathrm{x}$-ray lines from these particles appear for the most part to be restricted to elements of atomic number greater than iron.

The possibility that the particles are fallout from atomic bomb testing has been considered and has difficulties. For example, if atomic bomb debris can be carried upward through the stratosphere to an altitude of $85 \mathrm{~km}$ then the wide variety of terrestrial spores, salt particles, bits of mica, etc., found in the troposphere should also be elevated. Such is not the case. Furthermore, Rauser and Fechtig (1972) have shown that noctilucent cloud particles measured at Kiruna, Sweden two days after our collection flight were entering the mesopause from above and falling downward through it. In addition, it has been many years since any known space tests of atomic devices have been carried out and furthermore such an origin would appear to require too large a mass of fissioned material and a high efficiency mechanism for concentrating particles into the Polar regions.

The possibility that supernova particulate remnants have been encountered has also been suggested and appears to have even more severe difficulties although Greenberg (1969) has suggested that an interstellar component of dust might exist in the solar system. Additional measurements and flight collections will be necessary before the origin of these intriguing and unexpected particles can be identified.

The author expresses his thanks to Douglas Hallgren, Anthony Laudate, David Wachtel, Helga Schroeder, Gail Heylmun, Richard Schwarz and William Radigan for many hours of sample scanning and analysis. My thanks go also to James Lease of Goddard Space Flight Center. I wish to thank George Witt and Nathan Wilhelm of MISU and Ralph Carnevale of AFCRL and the Swedish Space Technology groups for their support in Sweden.

\section{REFERENCES}

Greenberg, J. M., 1969. A possible inter-relation between interstellar and interplanetary cosmic dust, Space Research IX, 111-115.

Hallgren, D. S., and Hemenway, C. L., 1970. Sounding rocket samplings of cosmic dust, Space Research XI, 377-381.

Hemenway, C. L., and Hallgren, D. S., 1970. Time variation of the altitude distribution of the cosmic dust layer in the upper atmosphere, Space Research $X, 272-280$.

Hemenway, C. L., Soberman, R. K., and Witt, G., 1964. Sampling of noctilucent cloud particles, Tellus, 16, 84-88.

Rauser, P., AND Fechtig, H., 1972. Combined dust collection and detection experiment during a noctilucent cloud display above Kiruna, Sweden, Space Research XII, 391-402. 